\title{
O LUGAR DAS TECNOLOGIAS DIGITAIS NO TRABALHO DOCENTE EM TEMPOS DE ENSINO REMOTO
}

\author{
Analigia Silva ${ }^{1}$ \\ Dhttps://orcid.org/0000-0002-3232-323X
}

Flavia Magrinelli Wegrzyn Martinez ${ }^{2}$

(Dhttps://orcid.org/0000-0003-3540-4032

Resumo: Diante do cenário determinado pela COVID-19, professores viram-se impelidos ao uso das tecnologias digitais em suas práticas pedagógicas. Assim, o objetivo deste estudo consistiu em identificar e analisar as relações estabelecidas com as TDIC por professores da Educação Infantil ao Ensino Superior, em contexto pedagógico determinado pelas condições sanitárias da COVID-19. A pesquisa assumiu abordagem quali-quantitativa. Como participantes do estudo, temos oitenta e quatro professores de cinco regiões do país. Os dados apontam que o momento pandêmico aligeirou e impôs o uso das tecnologias digitais no processo de ensino e aprendizagem, sem que o professor tivesse formação inicial ou contínua para a inserção desses recursos em suas práticas. Apesar disso, observamos que tal situação levou a uma reflexão sobre se considerar os determinantes atuais, especialmente as tecnologias digitais, nas práticas docentes a partir de uma perspectiva crítica e vinculada à formação integral do aluno.

Palavras-chave: trabalho docente; tecnologias digitais; ensino remoto.

${ }^{1}$ Licenciada em Pedagogia pelo IBILCE/UNESP. Mestre e Doutora em Educação pela PPGE/FCT/UNESP. Professora colaboradora na UENP - Universidade Estadual do Norte do Paraná (Centro de Ciências Humanas e da Educação- CCHE). E-mail: analigiamiranda@gmail.com

2 Doutora em Educação (UEPG); Mestre em Educação (UEPG); Especialista em Docência do Ensino Superior; Especialista em Saúde Para Professores do Ensino Fundamental e Médio; Graduada em Licenciatura em Ciências Biológicas e Pedagogia. Professora Colaboradora da Universidade Estadual do Norte do Paraná - UENP / CJ- Centro de Ciências Humanas e da Educação- CCHE / Colegiado de Pedagogia; Professora da Faculdade de Educação, Administração e Tecnologia de Ibaiti - FEATI no curso de pedagogia. E-mail: fwmartinez@uenp.edu.br 


\section{THE PLACE OF DIGITAL TECHNOLOGIES IN TEACHING WORK IN TIMES OF REMOTE TEACHING}

Abstract: In view of the scenario determined by COVID-19, teachers found themselves impelled to use digital technologies in their pedagogical practices. Thus, the objective of this study was to identify and analyze the relationships established with TDIC by teachers from Early Childhood Education to Higher Education, in a pedagogical context determined by the health conditions of COVID-19. The research took a quali-quantitative approach. As study participants, we have eighty-four teachers from five regions of the country. The data show that the pandemic moment eased and imposed the use of digital technologies in the teaching and learning process, without the teacher having initial or continuous training for the insertion of these resources in his practices. Despite this, we observed that this situation led to a reflection on whether to consider the current determinants, especially digital technologies, in teaching practices from a critical perspective and linked to the integral education of the student.

Keywords: teaching work; digital technologies; remote teaching.

\section{EL LUGAR DE LAS TECNOLOGÍAS DIGITALES EN EL TRABAJO DOCENTE EN TIEMPOS DE ENSEÑANZA A DISTANCIA}

Resumen: Ante el escenario determinado por COVID-19, los docentes se vieron impulsados a utilizar tecnologías digitales en sus prácticas pedagógicas. Así, el objetivo de este estudio fue identificar y analizar las relaciones que establecen con el TDIC los docentes desde Educación Infantil hasta Educación Superior, en un contexto pedagógico determinado por las condiciones de salud del COVID-19. La investigación adoptó un enfoque cuali-cuantitativo. Como participantes del estudio, tenemos ochenta y cuatro profesores de cinco regiones del país. Los datos muestran que el momento pandémico facilitó e impuso el uso de tecnologías digitales en el proceso de enseñanza y aprendizaje, sin que el docente tenga una formación inicial o continua para la inserción de estos recursos en sus prácticas. A pesar de ello, observamos que esta situación llevó a una reflexión sobre si considerar los determinantes actuales, especialmente las tecnologías digitales, en las prácticas docentes desde una perspectiva crítica y vinculada a la formación integral del alumno.

Palabras clave: trabajo docente; tecnologías digitales; enseñanza remota. 


\section{Introdução}

Por meio das tecnologias digitais de informação e comunicação (TDIC), temos acesso a informações e dados disponíveis de forma imediata, experimentamos a inexistência de fronteiras socioculturais, e vivemos uma sociabilidade calcada na mediação eletrônica. A conexão simultânea, propiciada pelos novos recursos digitais, alterou nossas percepções sobre espaço e temporalidade. A linearidade, a informação estanque, e as limitações entre espaço e tempo deram lugar aos "nós" da rede, que transformam os saberes que ali circulam em algo flexível, determinado pela fluidez e indefinição. Nesse processo, observamos um campo em construção que se estabelece nas formas de produzir, manipular e dispor o acesso às informações, culminando em novas formas de consumo, comportamentos e mentalidades. Vemos assim o surgimento de uma forma emergente e contemporânea de cultura, a chamada cibercultura (LÉVY, 2010), que incide, direta e indiretamente, na formação dos indivíduos dentro e fora da escola.

Evidenciamos que as novas gerações se apropriam diretamente das mudanças tecnológicas; e isso é um fator importante quando pensamos a educação escolar, pois, enquanto espaço formativo institucionalizado, a escola deve considerar em suas práticas as mudanças nas maneiras de significar o mundo pelas quais passa a sociedade. Nesse sentido, esta pesquisa se volta para a compreensão sobre as formas de apropriação de professores sobre as tecnologias digitais em contexto contemporâneo, permeado por determinantes atuais que impõem o uso de recursos digitais em contextos de ensino e aprendizagem.

Cabe ressaltar que este estudo parte de uma pesquisa maior, vinculada ao GEPE3, que tem o objetivo de analisar a concepção dos professores iniciantes sobre o trabalho docente no período de isolamento social devido a COVID-194. A hipótese levantada por esta pesquisa é a de que as variáveis que impactam o trabalho docente e a forma como a categoria docente é compreendida em seu aspecto profissional em contexto anterior à pandemia, são ainda mais acentuadas neste momento de crise sanitária. Diante do cenário determinado pela COVID-19, os professores viram-se

\footnotetext{
3 Grupo de Estudos e Pesquisa em Educação - GEPE (UENP/CJ).

4 Projeto submetido ao Comitê de Ética (UENP/CJ). CAEE: 35325120.4.0000.8123.
} 
impelidos ao uso das tecnologias digitais de forma aligeirada e determinada por um contexto impositivo, dadas as condições de afastamento social e o estabelecimento do ensino remoto5. Assim, o objetivo deste estudo consistiu em identificar e analisar as relações estabelecidas com as TDIC por professores da Educação Infantil ao Ensino Superior, em contexto pedagógico determinado pelas condições sanitárias da COVID-19. Abordaremos, neste artigo, questões contextuais, geracionais e formativas relacionadas ao uso das TDIC a partir de uma perspectiva sociointeracionista, uma vez que consideramos as tecnologias digitais enquanto instrumentos psicológicos com capacidade mediadora na promoção de processos inter e intramentais.

\section{As tecnologias digitais e a perspectiva histórico-cultural de L. S Vygotsky: elementos para reflexão}

Um pilar da teoria vygotskyana remete ao fato de que o funcionamento mental é definido pela mediação entre instrumentos e signos. As relações homem-mundo ocorrem entrepostas por ferramentas e signos advindos da cultura. Para Vygotsky (1996), a internalização de instrumentos e signos propicia o desenvolvimento cognitivo. Assim sendo, o homem é capaz de operar mentalmente sobre aspectos do mundo que o cerca, ou seja, representar simbolicamente objetos e fatos do mundo, gerando desenvolvimento social e cultural. Nesse processo, a linguagem ocupa lugar central, pois "o desenvolvimento do pensamento é determinado pela linguagem, isto é, pelos instrumentos linguísticos do pensamento e pela experiência sociocultural da criança". (VYGOTSKY, 1996, p. 44).

Nesse sentido, o homem tem acesso ao mundo que o cerca, todavia tal acesso não é direto, mas mediado, e o uso de instrumentos e signos é o que permite o desenvolvimento das funções psicológicas superiores, sendo essas a "combinação entre instrumento e o signo na atividade psicológica" (VYGOTSKY, 1998, p. 73). Acerca da internalização das funções psicológicas superiores, Vygotsky (1998, p. 75) aponta para uma série de transformações, sendo elas:

\footnotetext{
5 Modalidade de ensino constituída por aulas síncronas e assíncronas por meio de ferramentas virtuais que, no contexto de afastamento social devido à COVID-19, possibilitou a continuidade do ano letivo em instituições de ensino.
} 
a) uma operação que inicialmente representa uma atividade externa é reconstruída e começa a ocorrer internamente [...].

b) um processo interpessoal é transformado num processo intrapessoal [...].

c) a transformação de um processo interpessoal num processo intrapessoal é o resultado de uma longa série de eventos ocorridos ao longo do desenvolvimento.

Instrumentos e signos, entendidos como construções históricas e sociais, são internalizados pelo sujeito, propiciando desenvolvimento cognitivo. Esse desenvolvimento ocorre, em um primeiro momento, externamente, ou seja, no nível social, e depois se internaliza em processo intrapessoal. O grupo social oferece ao sujeito um ambiente em que os objetos possuem significados, e a palavra é que faz a mediação simbólica entre o sujeito e o mundo.

Ensinar e aprender, na abordagem vygotskyana, se constitui, então, de um processo de atividade socialmente partilhada. Para Vygotsky (1998), a criança nasce inserida em um meio social no qual a mediação ocorre como processo de utilização da linguagem. O sujeito é, então, interativo, e é a mediação que o leva ao conhecimento. Portanto, o conhecimento parte das relações sociais e consequentemente carrega aspectos culturais, sociais e históricos, pois o "aprendizado humano pressupõe uma natureza social específica e um processo através do qual as crianças penetram na vida intelectual daquelas que a cercam" (VYGOTSKY, 1998, p. 115).

Consideramos que a abordagem histórico-cultural, tomando por fundamento a teoria de Vygotsky, também nos permite analisar a questão do impacto das tecnologias no desenvolvimento cognitivo humano por meio da compreensão das relações entre sujeito e instrumento/signo. As relações estabelecidas pelo sujeito com o mundo são, de acordo com a abordagem vygotskyana, mediadas por instrumentos e signos, e a internalização de ambos culmina no desenvolvimento cognitivo. A interação do sujeito com o mundo ou com o objeto do conhecimento é necessariamente um acesso mediado. Sobre isso, Coll, Mauri e Onrubia (2010, p. 76) apontam que considerar as tecnologias em sua potencialidade educativa é encará-las como:

Ferramentas para pensar, sentir e agir sozinhos e com os outros. este argumento se apóia na natureza simbólica das tecnologias da informação e da comunicação em geral, e das tecnologias digitais em particular, assim como nas possibilidades inéditas que as TIC oferecem 
para procurar informação e acessá-la, representá-la, processá-la, transmiti-la e compartilhá-la.

A natureza simbólica das tecnologias, a possibilidade de acesso à informação, a interação social e a consequente experiência sociocultural permitida por elas levam o sujeito a operar mentalmente ou se desenvolver cognitivamente. Além disso, Vygotsky (1998) explicita que a internalização das funções psicológicas superiores se dá por meio de dois processos. Primeiramente, em um nível interpessoal e após a ocorrência de eventos que se desenrolam ao longo do desenvolvimento, há a transformação do processo interpessoal para o processo intrapessoal. Assim, o processo de ensino e aprendizagem, sob a perspectiva vygotskyana, pressupõe como potencial das tecnologias o fato de serem dotadas de recursos que favorecem a atividade conjunta, interativa e produtiva entre sujeitos, presentes ou não no mesmo ambiente físico, proporcionando a mediação de processos intra e intermentais (COLL; MAURI; ONRUBIA, 2010). Cabe assim refletir sobre as apropriações dos alunos e professores frente a essas ferramentas para, então, ponderar sobre as suas possibilidades e limitações formativas.

\section{Nativos e imigrantes digitais: ensinar e aprender em contextos contemporâneos}

O entrelaçamento entre o uso das tecnologias digitais e a cognição é uma discussão importante quando pensamos em práticas pedagógicas. Os intensos e diversos usos das tecnologias digitais têm tecido novos espaços de acesso à saberes que culminam em uma ampla rede de ecologias cognitivas (LÉVY, 1994), as quais, direta ou indiretamente, adentram os processos escolares. Podemos relacionar o conceito de ecologias cognitivas às coletividades humanas e técnicas nas quais o conhecimento emerge, é construído e modificado a partir de inter-relações entre os indivíduos e sujeito e objeto. O conhecimento é um produto fruto de uma cognição que é distribuída entre os indivíduos, ferramentas, instrumentos e signos. Assmann (2000) pontua algumas questões sobre os aspectos cognitivos e relacionais, trazidas pela função mediadora das tecnologias digitais no cenário atual. Para o autor, no tocante à aprendizagem e ao conhecimento, chegamos a uma transformação sem precedentes das ecologias cognitivas, tanto das internas da escola, como das que lhe são externas, mas que interferem profundamente nela (ASSMANN, 2000, p. 7). 
As "tecnologias cognitivas" (CLARK, 2001) ou as tecnologias digitais, como computadores, redes de comunicação e dispositivos móveis, permitiram que os dados e a sua propagação se tornassem um processo partilhado, distribuído, onde operamos novos espaços de construção de conhecimento. Sobre isso, Clark (2001, p. 141, tradução nossa) aponta que a cognição é resultado de diferentes fatores biológicos, sociais, culturais e tecnológicos, não incluindo "somente corpo, cérebro e o mundo natural, mas recursos e dispositivos (papel, caneta, computador, instituições) que juntamente com nosso cérebro biológico aprende, amadurece e opera".

Cabe então tratarmos sobre a evolução histórica das tecnologias de informar e comunicar, as quais, enquanto produtos da cognição humana, nos revelam contextos sócio-históricos e a dinâmica social e de produção de conhecimento de cada momento da humanidade. A oralidade, a escrita e a atual era das redes determinam, em suas diferentes fases, os modos como o homem constrói, aprende e transmite saberes. Nesse sentido, os recursos tecnológicos alteram a nossa relação com o mundo quando modificam as dimensões relacionadas aos modos de produzir e comunicar a produção intelectual humana.

Em uma síntese histórica, temos a humanidade em sua fase representada pela oralidade, onde a informação linguística estava atrelada ao homem e restrita ao tempo e ao espaço que se insere. Nesse contexto, a possibilidade de disseminação e sistematização de saberes é rudimentar e localizada, pois o alcance social dos saberes produzidos ficava limitado à memória dos indivíduos e sua duração transitória, dadas as características dessa fase.

A fase escrita, seguida pela informação tipográfica, amplificou a capacidade humana de produzir e comunicar saberes, e contribuiu para a complexificação dos conhecimentos, já que, nesse momento, era possível mantê-los disponíveis e preservados de forma definitiva para o outro. A possibilidade de expansão do espaço e tempo, onde o conhecimento circula, determinou a objetivação e universalidade de acesso ao conhecimento produzido, também propiciado pela possibilidade de separação entre memória e sujeito, impossível na era da oralidade.

No atual cenário, as tecnologias digitais permitem o rompimento definitivo de tempo e espaço, possibilitando o acesso global e imediato às produções humanas. A digitalização da informação descortina novas possibilidades de construção e 
comunicação dos saberes, bem como mudanças do padrão de sociabilidade. Segundo Coll e Monereo (2010, p. 17),

Entre todas as tecnologias criadas pelos seres humanos, aquelas relacionadas com a capacidade de representar e transmitir informação ou seja, as tecnologias da informação e da comunicação - revestem-se de uma especial importância, porque afetam praticamente todos os âmbitos de atividades das pessoas, desde as formas e práticas de organização social até o modo de compreender o mundo, de organizar essa compreensão e de transmiti-la para outras pessoas. As TIC têm sido sempre, em suas diferentes fases de desenvolvimento, instrumentos para pensar, aprender, conhecer, representar e transmitir para outras pessoas e para outras gerações os conhecimentos adquiridos.

No bojo de tais transformações, temos as gerações que participam e se apropriam dessas novas condições. A transformação é constante e tende a se intensificar na medida em que as tecnologias se fazem cada vez mais presentes em nosso cotidiano, em seus diferentes usos e constantes inovações. Isso é um fator importante quando pensamos na educação escolar atual, pois a escola, como espaço formativo, deve considerar, em suas práticas, as mudanças nas formas de aprender e significar o mundo pelas quais passa o seu aluno, independente do teor de tais mudanças. Se estamos experimentando aspectos positivos ou negativos em relação à apropriação de informação e construção de saberes, tem-se ainda um terreno a ser explorado com infinitas nuances e múltiplas possibilidades sociais, culturais e históricas. Estamos falando de um campo em construção, mas que não isenta a escola de se posicionar e agir sobre esse momento, objetivando a formação crítica e humana do seu aluno. Nesse sentido, o professor deve ter formação para compreensão da contemporaneidade e suas implicações formativas em seus múltiplos aspectos, dentre os quais as tecnologias digitais são elementos importantes nas relações estabelecidas entre os indivíduos e os saberes, sejam eles científicos, do senso comum, ou os novos e aqueles em vias de construção.

Tomando que uma das relações básicas no campo escolar se dá entre aluno e professor, cabe elucidar o que a literatura aponta sobre os diferentes usos das tecnologias digitais por esses indivíduos. Em uma revisão da literatura, levantamos uma discussão sobre as tipologias adotadas para categorizar os sujeitos em suas relações com 
as tecnologias digitais. Apesar de apresentarmos as definições adotadas acerca da questão geracional nos usos das tecnologias digitais, compreendemos que o sujeito histórico-cultural possui modos de interação com as tecnologias digitais mais ou menos fluentes, independentemente de suas idades. Dessa forma, não consideramos o fator idade como determinante sobre o uso das tecnologias digitais no que diz respeito a apropriações e aspectos relacionados ao aprender. Nesse estudo, apontaremos o que a literatura nos apresenta acerca do assunto como forma de levantamento e reflexão sobre a temática.

Encontramos na literatura definições como "Veteranos ou Tradicionais (nascidos até 1945); Baby boomers (nascidos entre 1946-1969); Geração X (nascidos entre 1970-1980); Geração Y (nascidos entre 1981-1990); Geração Z (nascidos a partir de 1991)" (NOVELLI; HOFFMANN; GRACIOSO, 2011, p. 03), nativos e imigrantes digitais (PRENSKI, 2001), Geração NET (TAPSCOTT, 2010), dentre outras diversas definições. Embora haja outros termos relacionados às análises etárias em relação ao uso das tecnologias e possíveis alterações nos padrões comportamentais e de pensamento dos sujeitos contemporâneos, as definições de Tapscott (2010) e Prenski (2001) são as mais difundidas nas discussões atuais acerca da temática.

As tipologias adotadas para designar a relação dos sujeitos contemporâneos com as tecnologias digitais também são alvo de críticas sobre a sua validade e seu caráter binário, entre aqueles que fazem um uso intenso das tecnologias digitais e mudaram suas formas de aprender e de se socializar em relação àqueles que não participaram desse processo. Nessa perspectiva, o professor ocupa um lugar em que dificilmente sairá da condição de imigrante e, ao mesmo tempo, é impelido a mudar para dar conta de ensinar as novas gerações. Contudo, como já apontado, acreditamos que a fluência no uso das tecnologias digitais independe de idade. Concordamos com Bayne e Ross (2007) quando apontam que considerar os jovens como nativos digitais e que professores não fazem parte desse processo é algo simplista, uma visão acrítica e determinista do processo gerando,

Um sentido de inevitabilidade e impotência em torno desta construção particular do digital talvez possa explicar de alguma forma a adoção relativamente acrítica do e-learning por alguns educadores, e sua 
rejeição violenta, mas igualmente acrítica, por outros (BAYNE; ROSS, 2007, p. 4, tradução nossa).

Prenski (2001) revisitou as tipologias que cunhou e admitiu que as distinções entre nativos e imigrantes digitais deveriam ser abordadas por uma nova ótica, o que chamou de Digital Wisdom (sabedoria digital). Bottentuit Junior, Lisboa e Coutinho (2009, p. 285), citando Prenski, enunciam a sabedoria digital enquanto "uma sabedoria entendida como bom senso para usar as TIC como extensões das nossas capacidades cognitivas".

Sandford apud Bayne e Ross (2007), também propõe a definição de "colono digital" para aqueles considerados anteriores a esta geração mais jovem, afastando uma posição determinista e fechada em relação ao uso das tecnologias digitais e reconhecendo a geração nomeada de "colonos digitais" como construtora e participativa nesse novo cenário.

Duarte et al. (2012) revelam, a partir de estudos realizados nos últimos dez anos, que o saber utilizar os recursos técnicos não corresponde a habilidades cognitivas natas, como aponta o conceito de nativos digitais. As autoras defendem a ideia de que:

Não há evidências até o momento de que autodidaxia tecnológica se traduza, automaticamente, em autodidaxia cognitiva; os jovens dominam, sem a mediação de adultos, o uso de TI, mas não dominam, sozinhos, as tecnologias do pensamento abstrato/reflexivo, que são a base da autonomia intelectual na relação com TI (DUARTE et al., 2012, p. 133).

Concordamos com as autoras ao evidenciar que 0 pensamento abstrato/reflexivo depende da mediação do outro. A formação intelectual do sujeito precisa de práticas pedagógicas que contemplem como o aluno aprende e que vislumbre estratégias definidas para a formação de conceitos.

Selwyn (2009) revisitou a literatura sobre os jovens e as tecnologias digitais na Educação. O autor alerta para o fato de que há inconsistências e uma visão homogênea sobre o uso das tecnologias pelos jovens. Aponta também que não há pesquisas ou estudos empíricos que possam embasar as características apontadas aos nativos digitais. Além disso, enfatiza que é preciso ter um olhar mais amplo sobre a relação entre as 
tecnologias e os jovens, considerando "complexas interações e relações com o desenvolvimento social, econômico, políticos e culturais nos quais emergem estes usos". (SELWYN, 2009, p. 371).

A evolução humana transforma a própria cultura e consequentemente os processos cognitivos resultantes da relação entre o sujeito e o seu meio. $O$ desenvolvimento das tecnologias reflete o desenvolvimento cognitivo e cultural de uma sociedade quando transforma, por meio de seus usos, os aspectos sociais, econômicos, educacionais e de trabalho. Lévy (2007) corrobora a afirmação ao apontar que as relações entre homem, trabalho e sua inteligência dependem das transformações e dos novos usos das diversas tecnologias de informar e comunicar. Nesse sentido, é preciso pensar a formação do professor e sua prática quando permeada pelas tecnologias digitais. No caso específico tratado nesse artigo, trazemos a inserção das tecnologias na prática docente de forma aligeirada, imposta pelo contexto do novo coronavírus. Portanto, expressamos a necessidade de avaliar a forma que os professores percebem esse momento em relação às suas práticas e como as questões contextuais contemporâneas permeiam as relações desses profissionais com os recursos tecnológicos.

\section{Percurso metodológico}

Para responder ao objetivo de analisar as concepções dos professores sobre o trabalho docente em período de isolamento social devido a COVID-19, a pesquisa assumiu a abordagem quali-quantitativa. Minayo e Sanches (1993, p. 247) explicitam que a pesquisa qualitativa "adequa-se a aprofundar a complexidade de fenômenos, fatos e processos particulares e específicos de grupos mais ou menos delimitados em extensão e capazes de serem abrangidos intensamente". No entanto, também apontam que o conjunto de dados de ordem quantitativa e qualitativa não se opõe, mas se complementam para abranger a complexidade do fenômeno pesquisado. Dessa forma, considerar pesquisas qualitativas não significa excluir dados quantitativos, mas pensar dialeticamente o universo da pesquisa. Triviños $(1987$, p. 66) diz que "o objeto, além da qualidade, tem a quantidade. Conhecer a quantidade de um objeto significa avançar no conhecimento do objeto".

Quanto aos objetivos, definimos essa pesquisa como exploratória. Nesse tipo de pesquisa podem ocorrer descrições e análises qualitativas e quantitativas do objeto de 
estudo, e o pesquisador deve estabelecer as inter-relações entre o fenômeno estudado e os dados analisados (MARCONI; LAKATOS, 2003).

Para coleta de dados, elaboramos um questionário semiestruturado, organizado a partir do objetivo geral, assim como os respectivos objetivos específicos propostos para o estudo. Na perspectiva de Minayo (2004, p. 108), o questionário semiestruturado "combina perguntas fechadas (ou estruturadas) e abertas, onde o entrevistado tem a possibilidade de discorrer sobre o tema proposto, sem respostas ou condições prefixadas pelo pesquisador". Logo, neste estudo, a justificativa para a escolha de perguntas fechadas se dá pelo fato de possibilitar caracterizar os sujeitos de acordo com seu perfil (faixa etária, gênero, cidade/estado em que reside, nível de escolaridade, etc.). Já para as perguntas abertas, essa escolha se justifica pela razão de permitir "ao informante responder livremente, usando linguagem própria, e emitir opiniões" (MARCONI; LAKATOS, 2003, p. 204).

Considerando o contexto pandêmico e a impossibilidade de contato presencial entre as pesquisadoras e os participantes, os questionários semiestruturados foram estruturados e aplicados por meio da plataforma on-line Google Forms, ferramenta que permite a criação de instrumentos de pesquisa personalizáveis para coleta e organização de dados.

Antes da aplicação junto aos participantes da pesquisa e tendo por base a perspectiva de que "o questionário precisa ser testado antes de sua utilização definitiva, aplicando-se alguns exemplares em uma pequena população escolhida" (MARCONI; LAKATOS, 2003, p. 203), realizamos testes-piloto com três professores voluntários, momento em que verificamos a clareza, possíveis vieses e efetuamos a reestruturação final do instrumento de pesquisa. Após a testagem do instrumento, divulgamos o questionário na rede social Facebook. Para tanto, elencamos duas categorias gerais para a divulgação, sendo: a) selecionar grupos dentro da rede social Facebook voltados para a categoria docente nas diferentes disciplinas e etapas do ensino (da Educação Básica a Educação Superior) e b) grupos que continham o número mais expressivo de participantes em cada disciplina e/ou etapa do ensino.

Na segunda etapa da pesquisa, selecionamos grupos de professores dos 26 estados do país mais o Distrito Federal. Nesse momento, as duas categorias 
anteriormente elencadas foram acrescidas pelos estados brasileiros, visando assim buscar a completude do estudo em todo o território nacional.

Obtivemos 84 professores que responderam ao instrumento de pesquisa. $\mathrm{O}$ perfil desses professores indica predominância do gênero feminino (71,4\%). Quanto às idades, temos $95,2 \%$ possuindo entre 25 e 40 anos. Sobre as suas formações na Educação Básica, temos predominância da educação pública (83,3\%). Sobre a formação em nível superior dos professores participantes, temos 41,4\% com Graduação e 56\% com pós-graduação (Especialização, Mestrado e/ou Doutorado). Acerca das regiões brasileiras, obtivemos a seguinte distribuição na relação entre região e número de professores participantes: Região Sul (51,81\%); Região Sudeste (20,48\%); Região CentroOeste (19,28\%); Região Nordeste $(6,02)$ e Região Norte $(2,41 \%)$.

Para a codificação e organização quantitativa dos dados coletados, utilizamos o IRAMUTEQ, software gratuito e desenvolvido sob a lógica da open source. Trata-se de um ambiente estatístico ancorado no software R e na linguagem python. O software permite cinco formas de organização dos dados: análises lexicográficas clássicas; por especificidades; método da classificação hierárquica descendente (CHD); análise de similitude, e nuvem de palavras. Nesse estudo, utilizamos a análise de similitude que se pauta na frequência de palavras e na teoria dos grafos, possibilitando identificar as coocorrências entre as palavras e possíveis relações existentes entre os termos.

Para análise qualitativa dos dados, trazemos a técnica da análise de conteúdo (BARDIN, 1977), procedimento de pesquisa que se assenta na linguagem. Além de ser um conjunto de técnicas de análise das comunicações, a finalidade da análise de conteúdo "é a inferência de conhecimentos relativos às condições de produção (ou, eventualmente, de recepção), inferência esta que recorre a indicadores (quantitativos ou não)" (BARDIN, 1977, p. 38). Produzir inferências faz com que a análise de conteúdo não seja meramente um procedimento puramente descritivo, e seja um procedimento que relaciona um dado com alguma teoria.

\section{Resultados e discussão}

As perguntas do instrumento aqui analisadas correspondem ao objetivo específico de identificar e analisar as relações estabelecidas com as TDIC por professores da Educação Infantil ao Ensino Superior, em contexto pedagógico determinado pelas 
condições sanitárias da COVID-19, sendo elas: "Qual suporte formativo você considera indispensável nesse período de aulas remotas?" "Em uma escala de o a 5, o quanto você se considera preparado(a) para atuar no ensino remoto? Justifique". "Como você considera sua relação com as tecnologias digitais e de informação e comunicação?"

A partir dos dados coletados e tratados no IRAMUTEQ, chegamos a uma árvore de similitude em que foram encontradas 2436 ocorrências e 129 segmentos de textos que se constituem nos seguintes blocos categoriais: aluno (25); aula (25); EaD (15), e plataforma (14).

No bloco categorial "aluno", observamos elementos que se alinham às diferenças metodológicas entre ensino presencial e ensino remoto; questões de acesso, tanto de professores quanto de alunos e necessidades formativas docentes. Vemos a complexidade de elementos que passaram a circular em torno de uma aula nesse momento de ensino remoto. Como exemplo, temos as seguintes falas docentes:

Como não temos garantia de que os alunos vão assistir às videoaulas e fazer as atividades, não tenho certeza se estão, de fato, aprendendo. Além disso, acho essencial a interação professor-aluno no processo de ensino e aprendizagem. Como vão tirar as dúvidas? $(P .10)^{6}$.

Há uma infinidade de recursos tecnológicos que existem e que facilitariam o ensino/aprendizado do aluno, muitos dos quais ainda não obtive acesso, além de metodologias que podem e devem ser usadas. Como não conheço todas, não me julgo completamente capacitado, há muito o que ser desbravado pela frente (P.6).

No meu caso, precisaria de mais informações sobre que tipo de acesso os alunos terão para que o professor possa planejar as aulas. Apesar dessas ferramentas, não tem como pensar em uma aula diferente para cada situação dos alunos (P.8).

Outra questão abordada dentro da categoria "aluno" pelos professores participantes é a realidade vivida por eles em relação à sua profissionalização na pandemia. Os docentes argumentaram acerca da sobrecarga do trabalho (para além da sobrecarga já sentida em contexto anterior à pandemia); falta de suporte técnico, e a

\footnotetext{
${ }^{6}$ Para preservar a identidade dos professores participantes, utilizamos códigos para nomeá-los. Cada entrevistado possui uma letra ( $\mathrm{P}=$ professor) e um número correspondente.
} 
imposição de uso das tecnologias sem a devida formação. Algumas falas revelam essa realidade vivenciada:

A pandemia pegou todos desprevenidos e essa nova modalidade de ensino também. Minha condição de trabalho é horrível! (P. 2).

Como não foi dado suporte nem pela rede municipal de ensino e muito menos pela escola, acaba que as condições de trabalho são problemáticas, visto que não existem horários determinados, diretrizes não claras e inconclusas, deixando os professores à mercê e cada um atuando como considera correto (P. g).

Bastante adaptado e exploratório, já que as horas/aulas e as demandas de trabalho aumentaram, o uso de equipamentos e recursos (wi-fi) e uso privado tiveram que ser disponibilizados sem aviso prévio. Tudo isso sem acréscimo e nem reajuste no salário (P. 16).

As condições de trabalho postas pela EAD não são as melhores, pois fomos impostos a funções para as quais os professores não estavam preparados, a plataforma EAD pode ser muito boa para nos dar várias alternativas, mas se não sabemos usar, do que ela serve? (P. 19).

Também tivemos respostas que se alinham às dimensões geracionais tratadas nesse estudo. Os professores participantes apontam os alunos enquanto nativos digitais e o professor como aquele que evolui junto à sociedade e enfrenta as mudanças de forma a adaptar-se a elas. Como exemplo, trazemos as seguintes falas:

\begin{abstract}
Alguns alunos não possuem internet com boa velocidade, mas mesmo assim estão empenhados. Sinto que eles gostam dessa metodologia, são nativos digitais e assim se torna mais interessante para eles, o que favorece a aprendizagem (P.13).

Qualquer professor formado para atuar em sala de aula nunca estará preparado para atuar em frente a um computador ou web site. Evoluímos juntos, estamos buscando ferramentas novas todos os dias e é esse anseio de tentar levar alguma informação para nossos alunos que ainda nos motiva a prosseguir nesse caminho (P. 7).
\end{abstract}

Cabe apontar que a perspectiva adotada em nosso estudo compreende o homem como sujeito histórico-cultural que possui modos de interação com as tecnologias digitais, mais determinados pelo entorno em que vive em detrimento do fator idade. Inferimos, pelas falas docentes, que, apesar de haver uma perceptiva do aluno enquanto nativo digital, os professores também se colocam como aquele que, a 
partir da dimensão da formação contínua e da sua inserção na contemporaneidade, procuram acompanhar e participar dos determinantes atuais.

Na dimensão "aula", encontramos elementos também relacionados à formação docente, como a ausência de capacitação para o ensino remoto ou para o uso de tecnologias digitais. As falas abaixo revelam essa dimensão:

O ensino remoto veio para desafiar a todos, pois tivemos que buscar as tecnologias e refletir as metodologias que seriam mais eficazes para esse momento. Eu senti muita dificuldade, no início principalmente, que assumi uma sala que estava em andamento e por ser processo de alfabetização. Dessa maneira, busquei cursos em relação à tecnologia e metodologias na alfabetização, me ajudou muito (P. 5).

De acordo com essa profissão, é necessário ser criativo e buscar sempre novas informações para atender os alunos, porém nossa formação prepara para o chão da escola, para o contato diário, e não para as aulas a distância (P. 15)

Eu não conhecia as plataformas, e não me considero com as habilidades tecnológicas necessárias para trabalhar dessa forma tento todos os dias, mas a dificuldade é grande (P.19).

Como foi algo repentino, não houve tempo suficiente para um treinamento adequado, quem não possuía habilidades com essa ferramenta teve mais dificuldade (P.25).

As posições de autores que discutem questões relacionadas à formação docente afirmam que os professores devem conhecer profundamente os meios digitais e as suas linguagens, bem como as questões relacionadas à aprendizagem e as implicações sociais, culturais e formativas com o uso desses meios (COLL; MONEREO, 2010; MOREIRA; KRAMER, 2007). Para lidar com esse momento, seria crucial que o professor compreendesse as transformações contemporâneas e como tais mudanças afetam o seu trabalho, além de ser capaz de, a partir da posse desses conhecimentos, atuar na formação sólida e crítica do alunado. Como afirma Contreras (2002, p. 84),

[...] ao ser o ensino uma prática social cuja realização não depende só das decisões tomadas pelos docentes em suas salas de aula, mas de contextos mais amplos de influência e determinação, a competência profissional deve ser colocada em relação com a capacidade de compreensão da forma em que estes contextos condicionam e mediam 
seu exercício profissional, bem como a capacidade de intervenção nesses âmbitos.

No contexto pandêmico, temos que as transformações advindas com a introdução tecnologias digitais na escola afetaram, incontestavelmente, a prática docente. Nesse cenário, é primordial que o professor compreenda a nova realidade a fim de construir a sua práxis, assim como o seu papel enquanto formador. Por outro lado, é preciso que o professor tenha criticidade para a compreensão sobre até que ponto inserir tecnologias na escola se alinha aos processos de aprendizagem ou à simples inserção inócua que apenas cumpre a determinação imposta e desvinculada de propósito, de fato, formativo. Inferimos que os professores participantes têm essa dimensão crítica quando apontam que o momento atual com a atual inserção das TDIC nos processos de ensino de aprendizagem:

Não é perfeito, estaria sendo um sonhador se dissesse o contrário. É possível notar que o conteúdo está sendo absorvido pelos alunos, mas há uma defasagem que pode ser observada nas atividades, alguns pontos que seriam solucionados se na sala de aula estivéssemos. Mas do que aprender, o aprender a aprender está de lado, isso é algo que aflige e frustra (P. 6).

Sinceramente, não sei se alcanço os objetivos que alcançaria na aula presencial. Será mesmo que os alunos estão aprendendo ou só cumprindo tarefas? (P.27).

Não estudei para dar aula a distância, é muito incômodo ter que dar conta de tudo, da casa, do filho, dos planejamentos de aula, dos preenchimentos documentais exigidos pela SME e direção da escola. Além de ver que está sendo em vão, pois os alunos, pelo menos da minha turma de $5^{\circ}$ ano, onde os conteúdos são um pouco mais complicados, encontram muitas dificuldades de apreensão $e$ socialização pelo meio tecnológico utilizado: Whatsapp. Não é a mesma coisa que na sala de aula, onde as coisas acontecem de forma dinâmica entre professor e aluno. Alguns nem entram no grupo para ver a explicação do conteúdo (P. 1).

As categorias "EaD" e "plataforma" se inter-relacionam, uma vez que se complementam nas suas características. Nessas dimensões, temos falas docentes que vão ao encontro das especificidades técnicas vinculadas ao ensino remoto que, segundo os professores participantes, resultam em dificuldades, necessidades de novas habilidades e adaptações necessárias. De acordo com os professores participantes: 
Está sendo algo novo para todo mundo, mas estou buscando fazer o melhor para levar o ensino para casa de uma maneira qualificada. Com o tempo, estamos aprendendo e se superando cada dia mais, buscando sempre estar muito preparada para atuar no ensino remoto ( $P$. 12).

É diferente trabalhar dentro da sala de aula e enxergando seu aluno e as dificuldades deles. E, para mim, também é diferente, pois não estou acostumada com isso, é bastante inovador, temos que nos adaptar, é claro, mas leva tempo (P. 14).

Indo ao encontro de Mamede-Neves e Duarte (2008), observamos que os professores participantes, apesar das dificuldades encontradas, se colocam alinhados à contemporaneidade e veem a necessidade de novos saberes relacionados a esse contexto. Inferimos a inexistência de uma discussão nas escolas dos professores participantes da pesquisa sobre as tecnologias digitais e as relações com os processos de ensino e aprendizagem. Parece-nos que a inserção das tecnologias digitais na escola se deu apenas pelo contexto pandêmico, uma vez que os professores expressam como sendo novidade o pensar sobre práticas docentes com o uso das tecnologias. Para Mamede-Neves e Duarte (2008, p. 785),

A escola terá melhores condições de cumprir seu papel de escolarizar as novas gerações de nativos digitais se conseguirmos levar em conta, na organização do currículo, nas práticas escolares e na escolha de nossos métodos, formas de aprender que não se enquadram em nossos paradigmas.

Em síntese, os dados apontam que o trabalho docente perpassa a consideração sobre a sociedade informacional, e o aluno que dela faz parte, quando comunica, se expressa e está em contato com outras formas de aprender, diferente das formas tratadas na escola, limitadas por tempo e espaço. Martins e Castro (2011, p. 621) apontam que as tecnologias digitais potencializam outras formas de "funcionamento cognitivo e intersubjetivo. Esses novos aparatos norteiam nossa relação com o mundo físico e social, trazendo transformações do olhar, da subjetividade e do conhecimento". Indo ao encontro da perspectiva vygotskyana de desenvolvimento humano, tomamos que as tecnologias digitais podem ser consideradas como artefatos culturais que se interpõem entre o homem e o meio em uma relação de reciprocidade. Essa realidade exige uma formação do professor para pensar suas práticas, considerando o momento 
histórico-cultural vivenciado. No entanto, o momento pandêmico aligeirou e impôs o uso das tecnologias digitais no processo de ensino e aprendizagem, sem que o professor tivesse formação inicial ou contínua para a inserção desses recursos em suas práticas. Apesar disso, observamos que tal situação levou a uma reflexão sobre as questões da contemporaneidade e observação da necessidade de se considerar os determinantes atuais nas práticas docentes a partir de uma perspectiva crítica e vinculada à formação integral do aluno. Inferimos que os professores participantes reconhecem a necessidade de se compreender o lugar das TDIC na sociedade e consequentemente na educação, e têm uma postura crítica sobre como tais ferramentas se apresentam na escola hoje. Em contexto pandêmico, se revelou a necessidade de formação, aliada à falta de estrutura técnica e aos investimentos públicos na área. Tal situação não se alinha ao planejamento e à avaliação de práticas pedagógicas críticas, formativas e contextualizadas.

\section{Considerações Finais}

A escola, como espaço formativo institucionalizado, deve considerar em suas práticas o atual contexto sociocultural, e contemplar os recursos digitais como estruturantes contemporâneos relacionados à formação humana, seja dentro ou fora da escola. Partimos do pressuposto de que a relação que os indivíduos estabelecem com as tecnologias digitais de informar e comunicar na atualidade vai além de considerá-las como fontes de acesso à informação, mas são instrumentos psicológicos mediadores de processos inter e intramentais, como nos aponta a perspectiva vygotskyana (VYGOTSKY, 1998). Nesse sentido, é preciso considerar as concepções docentes sobre as tecnologias digitais nos processos educativos. No contexto deste estudo, os professores se viram impelidos ao uso das tecnologias digitais de forma aligeirada e determinada por um contexto impositivo, dadas as condições sanitárias advindas com a COVID-19. Essa situação nos revelou que os professores têm uma percepção de ausência ou insuficiência sobre questões relacionadas às suas formações para os determinantes contemporâneos, especialmente sobre as tecnologias digitais e seus usos formativos e sociais. Tais questões foram trazidas associadas a uma reflexão contextualizada e crítica acerca das tecnologias digitais na contemporaneidade e na aprendizagem dos alunos.

A pandemia pela COVID-19 acentuou e denunciou aspectos da desprofissionalização docente, bem como a fragilidade formativa do professor para a 
compreensão e usos das tecnologias digitais em contextos educativos. Apesar disso, os professores participantes se posicionaram de forma crítica sobre esse cenário e expressaram suas necessidades formativas sobre os recursos digitais em contextos educativos. Cabe então trazer novos questionamentos e novas problematizações para o momento histórico vivenciado e as questões relacionadas ao professor, sua formação e a sua profissão na contemporaneidade.

\section{Referências}

ASSMANN, Hugo. A metamorfose do aprender na sociedade da informação. Ci. Inf., Brasília, v. 29, n. 2, p. 7-15, maio/ago. 2000. Disponível em:

https://www.scielo.br/pdf/ci/v2gn2/ao2v2gn2.pdf. Acesso em: 13 fev. 2021.

BARDIN, Laurence. Análise de conteúdo. Lisboa: Edições 70, 1977.

BAYNE, Siân; ROSS, Jen. The "digital native" and "digital immigrant": a dangerous opposition. In: ANNUAL CONFERENCE OF THE SOCIETY FOR RESEARCH INTO HIGHER EDUCATION. London: SRHE, 2007. p. 1-6.

BOTTENTUIT JUNIOR, João Batista; LISBÔA, Eliana Santana; COUTINHO, Clara Pereira. Podcast e Vodcast: o potencial da ferramenta VoiceThread. In: CARVALHO, A. A. A. (org.). Actas do encontro sobre podcasts. Braga: CIEd, 2009. p. 281-288. Disponível em: http://w3.ufsm.br/carmen/Objeto/Conteudo_html/oa/Arquivos/So5.pdf. Acesso em: 03 mar. 2021. Acesso em: 5 mar. 2021.

CLARK, Andy. Mindware: an introduction to the philosophy of cognitive science. New York: Oxford University Press, 2001.

COLL, César; MAURI, Teresa; ONRUBIA, Javier. A incorporação das tecnologias da informação e da comunicação na educação: do projeto técnico-pedagógico às práticas de uso. In: COLL, César; MONEREO, Carles (org.). Psicologia da educação virtual: aprender e ensinar com as tecnologias da informação e da comunicação. Porto Alegre: Artmed, 2010. p. 66-93.

COLL, César; MONEREO, Carles. Educação e aprendizagem no século XXI: novas ferramentas, novos cenários, novas finalidades. In: COLL, Carles (org.). Psicologia da educação virtual: aprender e ensinar com as tecnologias da informação e da comunicação. Porto Alegre: Artmed, 2010. p. 15-46.

CONTRERAS, José. A autonomia dos professores. São Paulo: Cortez, 2002.

DUARTE, Rosália. et al. O papel da escola no desenvolvimento de habilidades cognitivas no uso de mídias digitais. In: ENCONTRO NACIONAL DE DIDÁTICA E PRÁTICAS DE 
ENSINO - ENDIPE, 16., 2012, Campinas. Anais [...]. Campinas: FE/UNICAMP, 2012. p. 124139. Disponível em: http://endipe.pro.br/ebooks-2012/0083s.pdf. Acesso em: 6 mar. 2021.

LÉVY, Pierre. A inteligência coletiva: por uma antropologia do ciberespaço. 5. ed. São Paulo: Ed. Loyola, 2007.

LÉVY, Pierre. As Tecnologias da Inteligência: o futuro do pensamento na era da informática. Rio de janeiro: Editora 34, 1994.

LÉVY, Pierre. Cibercultura. Tradução de Carlos Irineu da Costa. $3^{\text {a }}$ ed. São Paulo: Editora 34, 2010.

MAMEDE-NEVES, Maria Apparecida Campos; DUARTE, Rosalia. O contexto dos novos recursos tecnológicos de informação e comunicação e a escola. Educ. Soc., Campinas, v. 29, n. 104, p. 769-789, out. 2008. Disponível em:

https://www.scielo.br/pdf/es/v29n104/a0729104.pdf. Acesso em: 12 fev. 2021.

MARCONI, Marina de Andrade; LAKATOS, Eva Maria. Fundamentos de metodologia científica. 5. ed. São Paulo: Atlas, 2003.

MARTINS, Luana T.; CASTRO, Lúcia R. de. Crianças na contemporaneidade: entre as demandas da vida escolar e da sociedade tecnológica. Revista Latinoamericana de Ciencias Sociales, Niñez y Juventud, Manizales, v. 2, n. 9, p. 619-634, jul./dez. 2011. Disponível em: https://www.redalyc.org/articulo.oa?id=77321592010. Acesso em: 6 mar. 2021.

MINAYO, Maria Cecília de Souza. O desafio do conhecimento: pesquisa qualitativa em saúde. 8. ed. São Paulo: Hucitec, 2004.

MINAYO, Maria Cecilia de S.; SANCHES, Odécio.Quantitativo-qualitativo: oposição ou complementaridade?. Cad. Saúde Pública, Rio de Janeiro, v. 9, n. 3, p. 239-248, jul./set. 1993. Disponível em: https://www.scielo.br/pdf/csp/vgn3/o2.pdf. Acesso em: 4 mar. 2021.

MOREIRA, Antonio Flavio Barbosa; KRAMER, Sonia. Contemporaneidade, educação e tecnologia. Educ. Soc., Campinas, v. 28, n. 100, p. 1037-1057, out. 2007. Disponível em: https://www.scielo.br/pdf/es/v28n100/a1928100.pdf. Acesso em: 6 mar. 2021.

NOVELLI, Valéria Aparecida Moreira; HOFFMANN, Wanda Aparecida Machado; GRACIOSO, Luciana de Souza. Reflexões sobre a mediação da informação na perspectiva dos usuários. Biblionline, João Pessoa, v. 7, n. 1, p. 3-10, 2011. Disponível em: https://brapci.inf.br/_repositorio/2011/og/pdf_d53b48d270_0018736.pdf. Acesso em: 6 mar. 2021.

PRENSKY, Marc. Digital natives, digital immigrants. On Horizon, [S. l.], v. 9, n. 5, p. 1-6, out. 2001. Disponível em: https://www.marcprensky.com/writing/Prensky\%20\%20Digital\%20Natives,\%20Digital\%2olmmigrants\%20-\%20Part1.pdf. Acesso em: 6 mar. 2021. 
SELWYN, Neil. The digital native - myth and reality. Aslib proceedings: new Information perspectives, London, v. 61, n. 4, p. 364-379, 2009. Disponível em:

http://tefkos.comminfo.rutgers.edu/Courses/Zadar/Readings/Selwyn\%2odig\%2onatives, \%20Aslib\%20Proceedings\%202009.pdf. Acesso em: 5 mar. 2021.

TAPSCOTT, Don. A hora da geração digital: como os jovens que cresceram usando a internet estão mudando tudo, das empresas aos governos. Rio de Janeiro: Agir Negócios, 2010.

TRIVIÑOS, Augusto Nibaldo Silva. Introdução à pesquisa em ciências sociais: a pesquisa qualitativa em educação. São Paulo: Atlas, 1987.

VYGOTSKY, Lev Semenovich. A formação social da mente: o desenvolvimento dos processos psicológicos superiores. São Paulo: Martins Fontes, 1998.

VYGOTSKY, Lev Semenovich. Pensamento e linguagem. São Paulo: Martins Fontes, 1996.

Recebido em: 30 junho 2021

Aceite em: 19 julho 2021 